\title{
A medical geology perspective of arsenic as a poison and medicinal agents
}

\author{
J.A. Centeno \\ Division of Biology, Chemistry and Materials Science, US Food and Drug Administration, Washington DC, USA
}

\begin{abstract}
The public health concerns for environmental exposure to arsenic has been recognized for decades. However, recent human activities have resulted in eve greater arsenic exposures and the potential increase for chronic arsenic poisoning on a worldwide basis.
\end{abstract}

\section{INTRODUCTION}

The public health concerns for environmental exposure to arsenic has been recognized for decades. However, recent human activities have resulted in eve greater arsenic exposures and the potential increase for chronic arsenic poisoning on a worldwide basis. The natural sources of arsenic exposure vary from burning of arsenic-rich coal (China) and mining activities (Malaysia, Japan) to the ingestion of arsenic-contaminated drinking water (Taiwan, The Philippines, Mexico, Chile). The groundwater arsenic contamination in Bangladesh and the West Bengal Delta of India has received the greatest international attention because of the large number of people potentially exposed and the high prevalence of arsenic-induced disease (Selinus et al., 2013).

\section{MEDICAL GEOLOGY - THE SCIENCE THAT DEALS WITH THE IMPACTS OF NATURAL GEOLOGIC MATERIALS}

Medical geology - the science that deals with the impacts of natural geologic materials and processes on animal and human health - is aimed at increasing the interactions between geoscientists, environmental and biomedical communities, and by stimulating increased research collaboration among these disciplines (Centeno, 2008; Centeno et al., 2016; Smith et al., 2010; Zikovsky \& Chah, 1990) Medical geologists are a group of scientists that are primarily interested in outbreaks of disease in which the characteristics of the local geological constituents contribute to the occurrence of various disease states. For the most part, diseases of interest have often included the effects of deficiency or toxicity of a variety of metallic and non-metallic elements on various systemic organs.
3 MEDICAL GEOLOGY - THE SCIENCE THAT COLLABORATES ON A WIDE RANGE OF ENVIRONMENTAL HEALTH PROBLEMS SEEKING CAUSES AND SOLUTIONS LS

Medical geologists are scientists (geoscientists, biomedical/public health scientists, chemists, toxicologists, epidemiologists, hydrologists, geographers, etc.) who generally collaborate on a wide range of environmental health problems seeking causes and solutions. Among these problems are the health impacts of geogenic (natural) dusts, naturally occurring elements in surface water, groundwater and soil, geologic processes such as volcanoes, erosions, earthquakes, tsunamis, etc., occupational exposure to natural materials and natural radiation, and long-term effects of exposure to oncogenic elements, the most prominent example being arsenic.

Medical geologists try to determine the sources, transport and fate of potentially harmful trace elements such as arsenic, fluorine, selenium, copper and other metals. They try to determine the pathways of exposure and produce maps that illustrate local, regional and/or global geologic and geochemical factors and their relationship to existing or potential health problems. A good example of collaborative research on medical geology is the arsenic issue in Bangladesh and West Bengal, India. In this region, medical geologists are working together to determine the source of the high arsenic levels in well water that put at risk the health of thousands of people in this region.

This presentation will focus on providing a medical geology perspective on arsenic as an environmental and medicinal agent. The discussion explores problems inferring risk and disease causation from natural exposures to arsenic, particularly for chronic outcomes, and will argue for the importance of the ecological perspective in assessing pathogenesis. Additionally, the potential beneficial aspects of arsenic as a medicinal agent will be explored. 


\section{REFERENCES}

Centeno, J.A. 2008. Foreword: 10th anniversary review: natural disasters and their long-term impacts on the health of communities. J. Environ. Monit. 10(2): 166-166.

Centeno, J.A., Finkelman, R.B. \& Selinus, O. 2016. Medical geology: impacts of the natural environment on public health. Geosciences 6(1): 8.

Selinus, O., Alloway, B.J., Centeno, J.A., Finkelman, R.B., Fuge, R., Lindh, U. \& Smedley, P. 2013. Essentials of medical geology. Springer, New York.
Smith, A.H., Lingas, E.O. \& Rahman, M. 2010. Contamination of drinking-water by arsenic in Bangladesh: a public health emergency. Bull. World Health Organ. 78(9): 1093-1103.

Zikovsky, L. \& Chah, B. 1990. The lognormal distribution of radon concentration in groundwater. Groundwater 28: 673-676. 